\title{
Downregulation of TGF-beta receptor types II and III in oral squamous cell carcinoma and oral carcinoma-associated fibroblasts
}

\author{
Wenxia Meng ${ }^{1}$, Qingjie Xia ${ }^{2}$, Lanyan Wu ${ }^{3}$, Sixiu Chen ${ }^{1}$, Xin He', Lin Zhang ${ }^{1}$, Qinghong Gao ${ }^{4 *}$, Hongmei Zhou ${ }^{*}$
}

\begin{abstract}
Background: The purpose of this study was to assess the expression levels for $T \beta R I, T \beta R I I$, and $T \beta R I I I$ in epithelial layers of oral premalignant lesions (oral leukoplakia, OLK) and oral squamous cell carcinoma (OSCC), as well as in oral carcinoma-associated fibroblasts (CAFs), with the final goal of exploring the roles of various types of T $\beta$ Rs in carcinogenesis of oral mucosa.

Methods: Normal oral tissues, OLK, and OSCC were obtained from 138 previously untreated patients. Seven primary human oral CAF lines and six primary normal fibroblast (NF) lines were established successfully via cell culture. The three receptors were detected using immunohistochemical (IHC), quantitative RT-PCR, and Western blot approaches.
\end{abstract}

Results: $\| H C$ signals for $T \beta R \|$ and $T \beta R I I I$ in the epithelial layer decreased in tissue samples with increasing disease aggressiveness $(P<0.05)$; no expression differences were observed for T $\beta R I$, in OLK and OSCC $(P>0.05)$; and T RRIl and TRRIII were significantly downregulated in CAFs compared with NFs, at the mRNA and protein levels $(P<$ 0.05). Exogenous expression of TGF- $\beta 1$ led to a remarkable decrease in the expression of T $\beta R I I$ and T $\beta R$ III in CAFs $(\mathrm{P}<0.05)$.

Conclusion: This study provides the first evidence that the loss of T $\beta R I I$ and TRRIII expression in oral epithelium

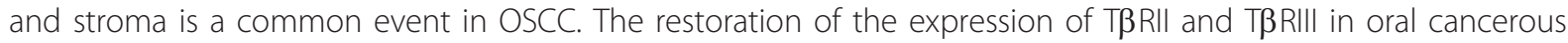
tissues may represent a novel strategy for the treatment of oral carcinoma.

\section{Background}

An increasing number of studies demonstrate that transforming growth factor beta (TGF- $\beta$ ) signaling pathway plays a dual role during the initiation and progression of human cancer; initially, it suppresses the formation of tumors, but elevated levels of TGF- $\beta$ promote the growth, progression, and migration of established tumors. Different explanations have been proposed for this dichotomous function of TGF- $\beta$, including the possibility that TGF- $\beta$ exerts tumorsuppressing effects on epithelial-derived tumor cells and tumor-promoting effects on stromal cells [1]. In general,

\footnotetext{
* Correspondence: qhgao@scu.edu.cn; acomnet@126.com

${ }^{4}$ Department of Oral Oncology, West China Hospital of Stomatology, Sichuan University, Sichuan, China

${ }^{5}$ Department of Oral Medicine, West China Hospital of Stomatology, Sichuan University, Sichuan, China

Full list of author information is available at the end of the article
}

TGF- $\beta$ exerts its effect by binding to the TGF- $\beta$ type II receptor (T $\beta R I I)$ and by subsequently recruiting T $\beta R I$ for downstream cytoplasmic signaling via multiple parallel signaling pathways, including the SMAD proteins [2]. In addition, T $\beta$ RIII functions as a coreceptor to increase the binding of ligands to T $\beta$ RII. In a majority of human cancers and cell lines, the expression of T $\beta$ RI and T $\beta$ RII is altered at the protein and/or mRNA levels $[3,4]$.

The in-depth study of T $\beta$ RIII revealed that this receptor may have additional functions that are independent of ligand presentation. Ryan et al [5] showed that the expression of T $\beta$ RIII (or betaglycan) is downregulated or lost in human prostate cancers compared with benign prostate tissues, at the mRNA and protein levels. Recently, another group used in vitro cell culture and in vivo animal models to demonstrate that the restoration of T $\beta$ RIII expression in renal cell carcinoma resulted in a marked induction of apoptosis [6]. 
Human oral squamous cell carcinoma (OSCC) accounts for about $90 \%$ of malignant oral lesions. It is widely recognized as progressing in a multistep manner, with an initial presentation of premalignant lesions (among which oral leukoplakia (OLK) is the most common), and later development of hyperplasia and dysplasia, then in situ carcinoma, and finally invasive carcinoma [7]. However, the expression of the major components of the pathway, which include the systematic analysis of signaling receptors T $\beta R I, T \beta R I I$, and T $\beta$ RIII, remains intact in human OSCC $[8,9]$. The current study represents the first systematic analysis of the expression of T $\beta R I$, T $\beta$ RII, and T $\beta$ RIII during the process of oral epithelial carcinogenesis.

Recent studies strongly suggest that the clinical behavior of malignant tumors not only depends on alterations in the epithelial cells themselves, but is also affected by their interaction with the tumor-associated stroma. However, the components of these specialized stromal cells represent a complex network that includes inflammatory cells (lymphocytes, macrophages, and mast cells), activated fibroblasts, and cells comprising the vasculature. Therefore, it remains questionable whether one single factor will be the "magic bullet" of cancer therapy. Recent data bring prominence to the idea that activated fibroblasts (also termed carcinomaassociated fibroblasts (CAFs) or myofibroblasts) may be major players in the tumor stromal environment $[10,11]$. Their role as starting or supportive elements in carcinogenesis is also well established. Relevant studies of modified fibroblasts have been performed in several tumor systems $[12,13]$. Some of the systematic and important findings of our previous study suggest that oral CAFs promote the proliferation and invasion of the lingual carcinoma cell line Tca8113 in vitro by secreting the KGF (keratinocyte growth factor) and MMP-2 factors (matrix metalloproteinase) [14]. A recent study showed that TGF- $\beta$ signaling in fibroblasts modulated the growth and oncogenic potential of adjacent epithelia in selected tissues [15]. Moreover, downregulation of T $\beta$ RII was observed in colon-carcinoma-associated spindle-like stroma cells that apparently represented fibroblasts and myofibroblasts [14,16]. In our study, we directly separated and cultured oral CAFs in vitro from adjacent OSCC tissues and evaluated, for the first time, detected the expression levels of the three types of T $\beta$ Rs in oral CAFs.

\section{Methods}

\section{Tissue Specimens}

All surgically resected tissue specimens were obtained from the West China Hospital of Stomatology. For IHC analyses, 138 specimens representing four different clinicopathological stages (including 25 normal epithelium tissues, 21 OLK samples without dysplasia, 24 OLK samples with dysplasia, and 68 infiltrated OSCCs) were recruited from the archives of the Department of Oral Surgery and Oral Medicine. The 138 specimens included eight OSCC samples and paired normal tissues. The corresponding normal tissues were incised along a line that is surgically termed a safety border, which was verified via staining of frozen sections. All surgically resected tissues were collected, fixed in formalin, and embedded in paraffin for histopathological confirmation.

For primary cell cultivation, fresh and sterile tissue specimens (including OSCC and normal oral mucosal tissues) were placed immediately on Hanks Balanced Salt Solution (Gibco, USA) containing penicillin and streptomycin $(200 \mu \mathrm{g} / \mathrm{ml})$ after being collected from the patient. All samples contained the epithelium and adjacent connective tissues. The OSCC specimen was fresh and exhibited infiltration of the adjacent connective tissue. Connective tissues used for sectioning were collected as close as possible to the epithelium. The protocol was reviewed by the Institutional Ethics Committee of Sichuan University and informed consent was obtained from each patient.

\section{IHC Analysis}

Immunostaining for T $\beta$ RI and T $\beta$ RII (rabbit polyclonal antibodies; dilution, 1:200; Santa Cruz, USA) and T $\beta$ RIII (mouse monoclonal antibody; dilution, 1:200; Santa Cruz, USA) in human OSCC and tumor-associated stromal sections was performed using the DakoCytomation EnVision system (DakoCytomation Corporation, Carpinteria, CA), according to the manufacturer's instructions. Slides were counterstained with Modified Harris Hematoxylin. Immunoreactivity was scored as "-" (absent), "1+" (low, $\leq$ $25 \%$ of positive cells), " $2+$ " (moderate, $26-75 \%$ of positive cells), or " $3+$ " (diffuse, $>75 \%$ of positive cells) [9]. OSCCs were assessed based on at least 10 randomly selected fields. All slides were interpreted by two investigators.

\section{Isolation and Cultivation of Oral CAFs and NFs}

The specimens were analyzed using methods described previously[14]. Briefly, tissues were washed twice with phosphate-buffered saline (PBS) and antibiotics. Oral epithelial and adipose tissues were then separated from surrounding stromal cells. The residual connective tissue was cut into small pieces $(1 \times 1 \times 1 \mathrm{~mm})$ that were maintained in Dulbecco's modified Eagle's medium (DMEM, Gibco, USA, pH 7.2) containing 20\% fetal calf serum (Gibco, USA), glutamine $(20 \mu \mathrm{g} / \mathrm{ml})$, penicillin $(100 \mathrm{U} / \mathrm{ml})$, streptomycin $(100 \mu \mathrm{g} / \mathrm{ml})$, and $0.25 \%$ trypsinase (Gibco) at $37^{\circ} \mathrm{C}$ in an atmosphere containing $5 \%$ $\mathrm{CO}_{2}$. To purify the cells, we opted for a method of curettage combined with trypsinization, which was performed when cells covered the bottom of the culture 
bottle fully. Cultures at passage number three were used for the cellular identification of oral CAFs and NFs. A wide-spectrum $\alpha$-cytokeratin antibody (ZSGB-BIO, Beijing, Corp., China) was used to confirm the absence of contaminating epithelial cells. Finally, antibodies against vimentin (ZSGB-BIO, Beijing, Corp., China) and smooth muscle $\alpha$-actin (R\&D Systems) were used to confirm the myofibroblastic nature of these cells [17].

\section{Quantitative Real-Time PCR}

Total RNA was isolated from cells using the Trizol reagent (Invitrogen) and was quantified by analysis of absorbance at $260 \mathrm{~nm}$. Relative gene expression levels were calculated using the comparative threshold-cycle method of quantitative PCR, with data normalized to $\beta$-actin and expressed relative to untreated controls. Real-time PCR was performed using the SYBR PrimeScript ${ }^{\mathrm{TM}} \mathrm{RT}-\mathrm{PCR}$ kit II (TaKaRa, Dalian, China), according to the manufacturer's instructions. The primers used to amplify T $\beta$ RI, T $\beta$ RII, and T $\beta$ RIII were as follows: T $\beta$ RI sense, 5'-GGTCTTGCCCATCTTCACAT-3' and antisense, 5'-TCTGTGGCTGAATCATGTCT-3'; T $\beta$ RII sense, 5'-GTCTACTCCATGGCTCTGGT-3' and antisense, 5'-ATCTGGATGCCCTGGTGGTT-3'; and T $\beta$ RIII sense, 5'-TACAGAGAGAGGTCACACT-3' and antisense 5'-GTCTTCAGATGCCACACCAG-3'. The total volume used in PCR was $50 \mu \mathrm{L}$. PCR products $(5 \mu \mathrm{l})$ were analyzed by electrophoresis using $1.5 \%$ agarose gels and were visualized by SYBR Gold (Molecular Probes, Eugene, USA) staining. All experiments were performed in triplicate.

\section{Protein Preparation and Western Blot Analysis}

Protein extracts were prepared using a lysis buffer (RIPA) containing the protease inhibitor PMSF (RIPA: PMSF $=50: 1)$. For Western blot analysis, $\sim 80 \mu \mathrm{g}$ of protein was separated using $8 \%$ SDS-PAGE, which was followed by transfer onto a PVDF membrane (Millipore, USA) and probing with an anti-T $\beta R$ antibody (1:400, Santa Cruz, USA). The blots were incubated with horseradish-peroxidase-conjugated secondary antibodies $(1: 5,000)$ and visualized using an enhanced chemiluminescence detection system (Pierce Biotech Inc., Rockford, IL).

\section{Preparation of Cells Conditioned With the Human TGF- $\beta 1$ Cytokine}

To determine whether TGF- $\beta 1$ mediates the regulation of the expression of T $\beta$ RI, T $\beta$ RII, and T $\beta$ RIII, we assessed the levels of the T $\beta$ Rs using quantitative realtime PCR and Western blot analysis after treatment with TGF- $\beta 1$.

TGF- $\beta 1$ was obtained from Sigma (St. Louis, MO). CAFs or NFs cells were cultured for two consecutive days in medium containing $10 \%$ fetal calf serum and were then washed twice with PBS and cultured in serum-free medium containing $10 \mathrm{ng} / \mathrm{ml}$ of TGF- $\beta 1$. After $24 \mathrm{~h}$ of treatment, cells were washed and harvested for RNA and protein extraction.

\section{Statistical Analyses}

Differences between the groups were statistically evaluated using the unpaired Student's $t$ test. The chi-squared or K Independent Samples Tests were used to compare frequencies, when appropriate. Significance was set at $P<0.05$. All analyses were performed using the statistical software SPSS for Windows Version 13 (SPSS Inc., Chicago, USA).

\section{Results}

Expression of T $\beta R I, T \beta R I I$, and T $\beta R I I I$ in Human OSCC, Oral Leukoplakia, and Normal Tissues

To fully assess the expression of T $\beta$ RI, II, and III in clinical samples and determine their role in OSCC carcinogenesis and prognosis, 138 specimens were examined that represented four clinicopathological stages (including normal epithelium tissues, OLK without dysplasia, OLK with dysplasia, and infiltrated OSCCs). The clinical information of patients is shown in Table 1.

Our IHC results showed moderate-to-intense homogeneous cytoplasmic or membrane expression of T $\beta$ RI, II, and III in oral normal squamous epithelium. Homogeneous, moderate, and intense cytoplasmic expression of T $\beta$ R-I was observed in OSCC tissues and in OLK (Figure 1A-D; Figure 2A). However, T $\beta$ RII and T $\beta$ RIII staining in the four groups revealed a remarkable decrease in expression from normal oral specimens through OLK to OSCC (Figure 1E-L; Figure 2B and 2C),

\begin{tabular}{l} 
Table $\mathbf{1}$ Characteristics of the OSCC Tissue Samples Used \\
for IHC Analysis \\
\hline Age (years) \\
Sex \\
$\quad$ Male \\
$\quad$ Female \\
Histological type \\
$\quad$ Well diff. \\
$\quad$ Mod diff. \\
$\quad$ Poor diff. \\
T classification \\
T1 \\
T2 \\
T3 \\
T4 \\
N classification \\
N0 \\
N+ \\
\hline
\end{tabular}




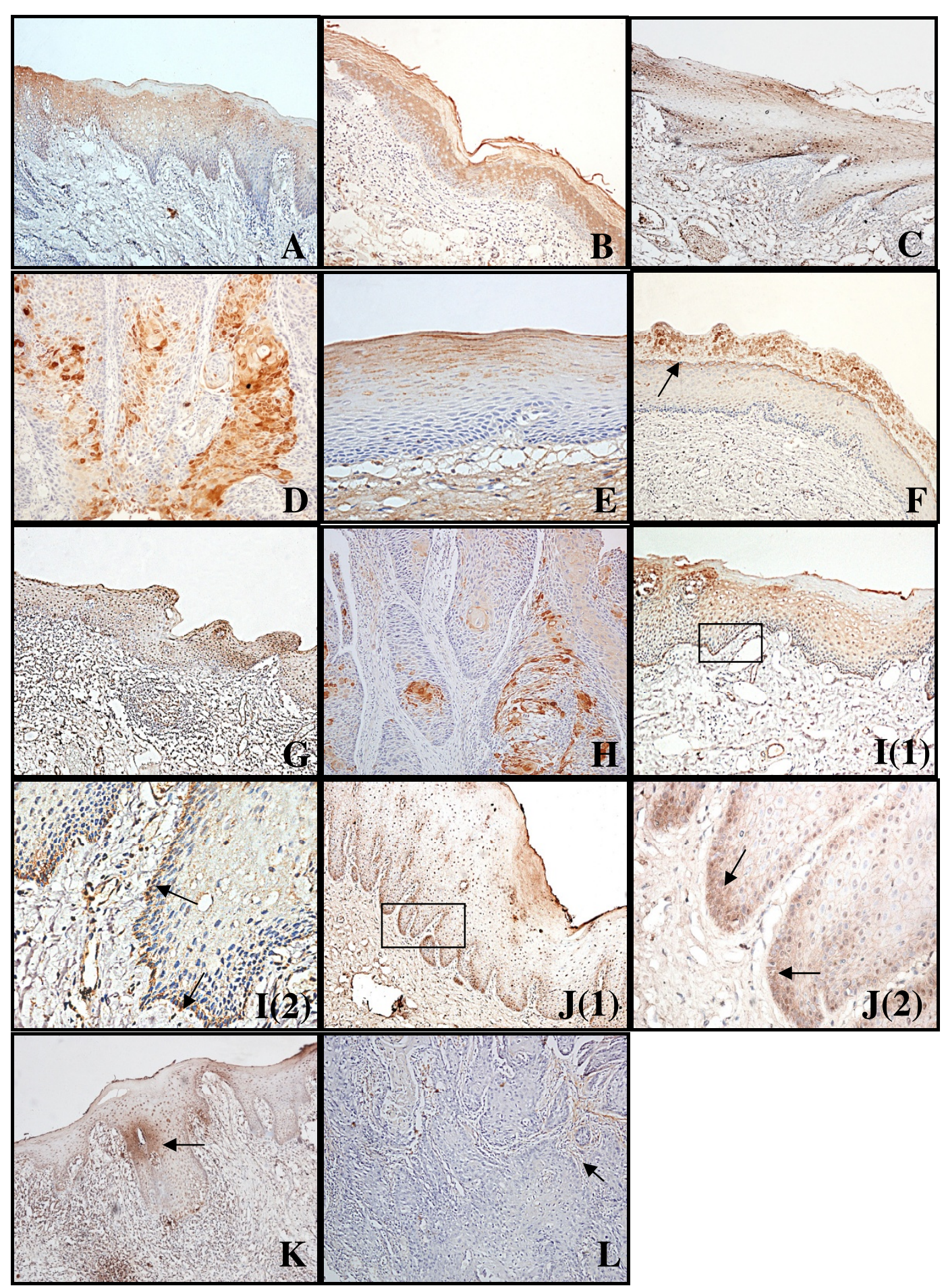

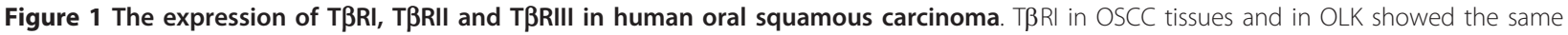
homogeneous, moderate, and intense cytoplasmic expression as in normal oral specimens (A-D). IHC analysis showed that the expression of

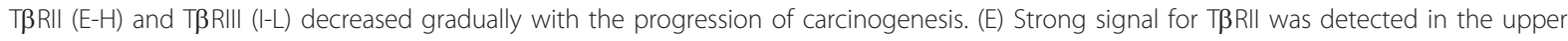
spinous and granular layers of normal specimens. (F) Positive staining was detected mainly in the granular layers and in cuticular layer (arrowhead) in OLK without dysplasia. (G) The immunostaining profile was decreased in OLK with dysplasia. (H) Significant downregulation of TBRII was observed in infiltrated OSCC. (I) Strong signal for TRRIII was detected in the basal layer and in the upper spinous in normal specimens (arrowhead). (J) Positive staining was significantly decreased in OLK without dysplasia and a stronger signal for TßRIII was detected in the basal layer. (K) The immunostaining profile was decreased in OLK with dysplasia. (L) Note the absence of TRRIII staining in OSCC tissues. Weak

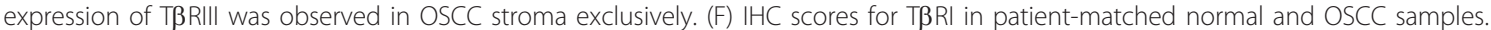



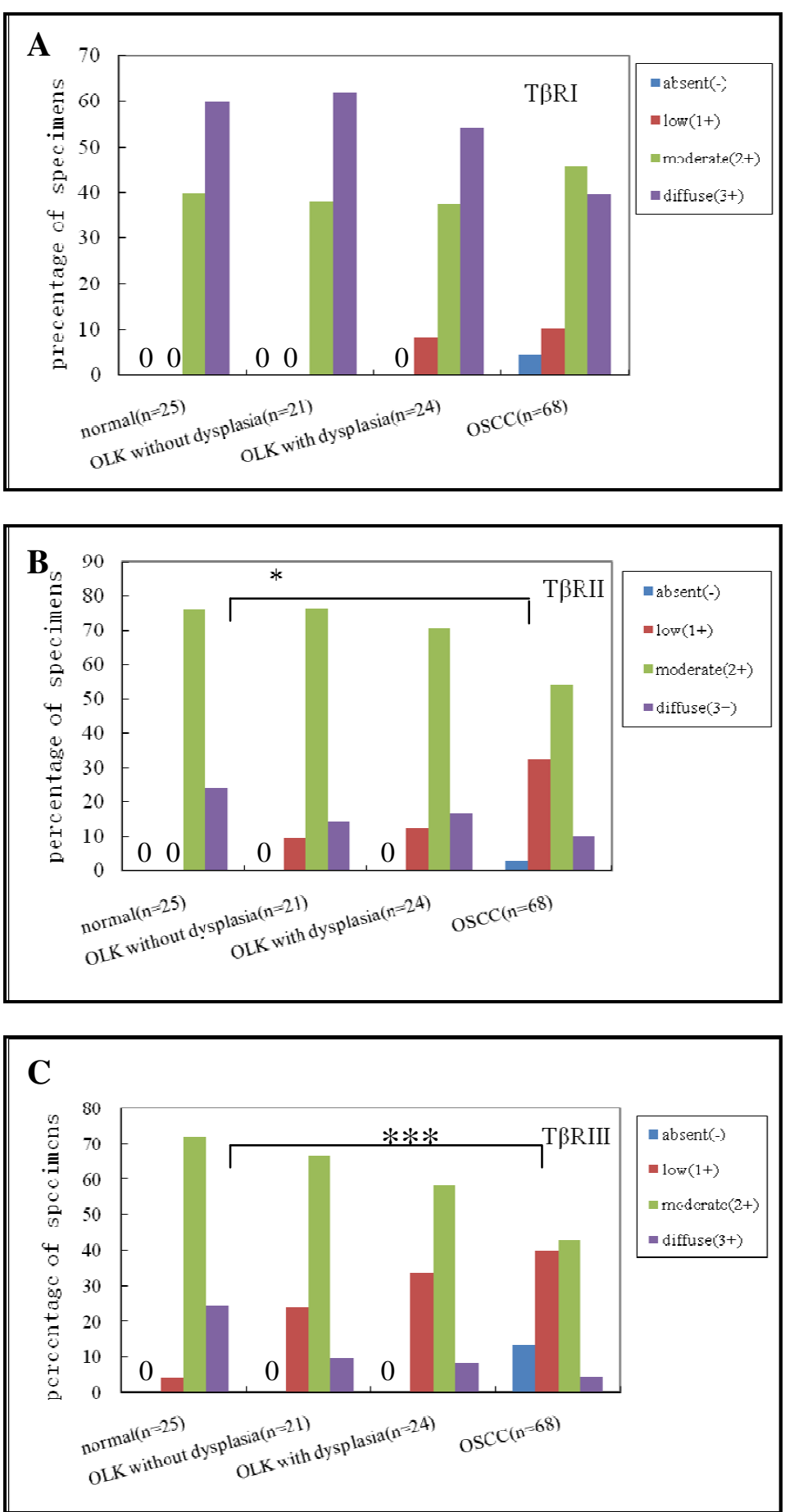

Figure 2 Summary of IHC results, with percentages shown. $(A: T \beta R I) P=0.116, K$ Independent Samples Tests. $(B: T \beta R I I) * * P=0.002, K$ Independent Samples Tests. (C: TRRIII) ${ }^{* * *} P<0.001, \mathrm{~K}$ Independent Samples Tests. When staining is not detected, we stated in the figure (0).

which was paralleled by an increase in the severity of epithelium dysplasia. Interestingly, we noted the upregulation of T $\beta$ RIII at the basal layer, both in normal epithelium and oral leukoplakia (Figure $1 \mathrm{I}(2), \mathrm{J}(2)$ ), whereas T $\beta$ RII expression was nearly absent in the two oral epithelia. However, a strong signal for TßRII was detected in the upper spinous and granular layers of normal oral epithelium, as well as in the cuticular layer, especially in the OLK cases (Figure 1F). The proportion of cells exhibiting diffuse T $\beta$ RII expression decreased 
from $24 \%$ in normal oral specimens to $10.3 \%$ in OSCC specimens. Concomitantly, the proportion of cells exhibiting low T $\beta$ RII expression increased from $0 \%$ in normal oral specimens to $32.4 \%$ in OSCC specimens $(P=$ 0.002, K Independent Samples Tests) (Figure 2B). The number of cells exhibiting diffuse T $\beta$ RIII expression decreased from $24 \%$ in normal specimens to $9.5 \%$ in OLK without dysplasia and $8.3 \%$ in OLK with dysplasia, and to $4.4 \%$ in OSCC specimens. In contrast, the proportion of cells with low T $\beta$ RIII expression increased from $4 \%$ in normal specimens to $23.8 \%$ in OLK without dysplasia and $33.3 \%$ in OLK with dysplasia, and to $39.7 \%$ in OSCC specimens $(P<0.001$, K Independent Samples Tests) (Figure $2 \mathrm{C}$ ). In addition, to address directly the role of the loss of T $\beta \mathrm{R}$ expression in OSCC progression, we assessed eight matched normal tissue samples and invasive OSCC specimens (Figure 3). The examination of T $\beta$ RII expression revealed that six cases exhibited a decrease in expression, from relatively high levels (IHC score, 2-3) in normal oral tissues to low expression levels (IHC score, 0-1) in the matching invasive OSCC tissues (Figure 3B). T $\beta$ RIII expression decreased from an IHC score of 2-3 in normal specimens to a score of 0 in OSCC specimens (Figure $3 C$ ). These data suggest that the expression of both T $\beta$ RII and T $\beta$ RIII was significantly downregulated in OSCC samples and that this loss of T $\beta$ RII and T $\beta$ RIII expression correlated with the development of OSCC (from normal tissues through OLK to OSCC).

\section{Identification of Oral CAFs and NFs}

Seven primary human oral CAF lines and six primary oral NF lines were derived from oral mucosa successfully using cell culture. The clinical information of the OSCC patients used for the establishment of primary CAF cultures is listed in Table 2. Normal tissues used for NF culture were collected from healthy individuals undergoing plastic or trauma surgery. We then verified the purity of the various fibroblast populations using immunostaining. These fibroblast populations were negative for cytokeratin, whereas they expressed fibroblastic marker vimentin, which suggests that some fibroblast traits were preserved in the CAFs (Figure 4). Importantly, cultured CAFs expressed traits of activated fibroblasts (myofibroblasts). Expression of alpha smooth muscle actin ( $\alpha$-SMA) is a defining characteristic of CAFs [10]. Using an anti$\alpha$-SMA antibody, we observed an increased proportion of $\alpha$-SMA-positive myofibroblasts in isolated CAF populations (Figure 4) compared with normal fibroblasts.

\section{Loss of T $\beta$ RII and T $\beta$ RIII Expression in CAFs Assessed Using RT-PCR and Western Blotting}

The mRNA expression levels of the three kinds of T $\beta$ Rs in CAFs and NFs were examined using quantitative real-time PCR. The expression of the T $\beta$ RIII mRNA in CAFs was downregulated by a factor of 11.37 and was significantly different from the control group $(P=$ $0.001)$. In addition, the expression of the T $\beta$ RII mRNA was reduced by a factor of 2.013 in CAFs compared with NFs $(P=0.004)$. T $\beta$ RI mRNA expression levels were not significantly different between CAFs and NFs $(P=0.362)$. Overall, the expression levels of the T $\beta R I$, T $\beta$ RII, and T $\beta$ RIII mRNAs, as assessed using RT-PCR analysis, were consistent with the immunocytochemistry results (Figure 5). Similarly, the expression of T $\beta$ RII and T $\beta$ RIII was decreased at the protein level in CAF cells compared with normal fibroblasts (Figure 6). No significant changes were observed regarding $\mathrm{T} \beta \mathrm{R} \mathrm{I}$ protein expression levels.

\section{TGF- $\beta 1$ Downregulated the Expression of T $\beta$ RII and T $\beta R I I I$ in Oral CAFs and in NFs}

Our results showed that T $\beta$ RIII and T $\beta$ RII were significantly downregulated in oral CAFs or in NFs after treatment with $10 \mathrm{ng} / \mathrm{ml}$ TGF- $\beta 1$, with a maximal downregulation at 6-12 h (Figure 5B-G). To assess whether the effects of TGF- $\beta 1$ on the expression levels of T $\beta$ RII and T $\beta$ RIII were specific, we analyzed the role of TGF- $\beta 1$ in the regulation of T $\beta$ RI levels in oral CAFs. In contrast with the results obtained for T $\beta$ RIII and T $\beta$ RII, TGF- $\beta 1$ treatment led to a slight increase in the levels of T $\beta R I$ (this result was not significant) (Figure 5A). Besides, TGF- $\beta 1$ could also downregulate the T $\beta$ RIII and T $\beta$ RII expression in NFs (Figure 6D). These results indicate that transcriptional and translational downregulation associated with increased expression of TGF- $\beta 1$ in an oral cancer microenvironment (especially in CAFs) may represent a mechanism that leads to oral carcinogenesis. We found that TGF- $\beta 1$ downregulated T $\beta$ RII and T $\beta$ RIII (and not only T $\beta$ RIII) in oral CAFs and in NFs.

\section{Discussion}

This study represents the first systematic demonstration of the downregulation of the TGF- $\beta$ receptors T $\beta$ RII and T $\beta$ RIII in human OSCC, with approximately $35.3 \%$ of OSCC specimens demonstrating low or absent expression of T $\beta$ RII and approximately $52.9 \%$ of specimens demonstrating low or absent expression of T $\beta$ RIII. This decrease in the expression levels of T $\beta$ RII and T $\beta$ RIII correlated with the progression of OSCC. We also demonstrated that loss of T $\beta$ RII and T $\beta$ RIII expression was an early event that occurred initially during the OLK stage. However, there was no significant difference in T $\beta R I$ expression between normal specimens and OLK or OSCC. Thus, we predict that loss of T $\beta$ RII and T $\beta$ RIII expression is the most common alteration in the TGF- $\beta$ signaling pathway described in human OSCC. 

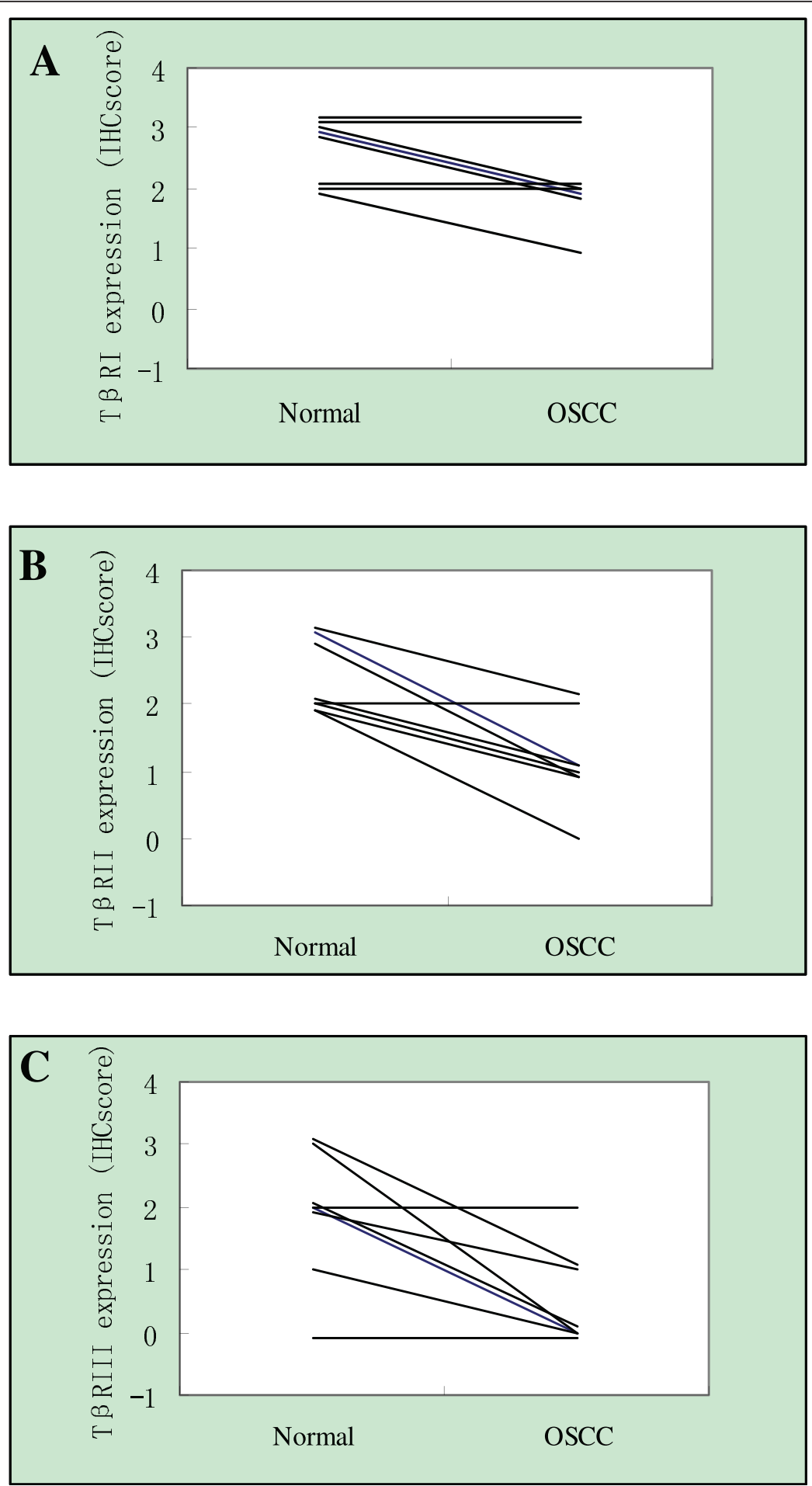

Figure $3 \mathrm{IHC}$ scores for T $\beta R \mathrm{RI}, \mathrm{T} \beta \mathrm{RII}$ and $\mathrm{T} \beta \mathrm{RIII}$ in patient-matched normal and OSCC samples.

Studies performed on other tumor tissues regarding TGF- $\beta$ receptors yielded similar results, and it has been described as having an association with carcinogenesis and tumorprogression $[16,18,19]$. Previous data showed T $\beta$ RIII can enhance TGF $\beta$-mediated inhibition of proliferation, invasion and angiogenesis. Reexpression of T $\beta$ RIII in vivo in renal cell carcinoma models induced striking apoptosis [6]. These results were consistent with our current study of tumor progression of oral cancer cells in which TGF- $\beta$ receptors were defective. The 
Table 2 Clinical and Pathological Data of OSCC Samples Used for CAF Cultivation

\begin{tabular}{|c|c|c|c|c|c|c|}
\hline Sample No & Sex & Age & Location & $\begin{array}{l}\text { Histological } \\
\text { type }\end{array}$ & TNM classification & Clinical stage \\
\hline 01 & Female & 38 & Tongue & Well diff. SCC & T1NOMO & I \\
\hline 02 & Female & 57 & Tongue & Well diff. SCC & T1N0M0 & I \\
\hline 03 & Female & 64 & Tongue & Mod. diff. SCC & T1N0M0 & I \\
\hline 04 & Male & 50 & Oral floor & Poor diff. SCC & $\mathrm{T} 2 \mathrm{~N} 2 \mathrm{MO}$ & IV \\
\hline 05 & Male & 62 & Gingival & Mod. diff. SCC & T2N2M0 & $\|$ \\
\hline 06 & Female & 71 & Gingival & Mod. diff. SCC & $\mathrm{T} 2 \mathrm{~N} 2 \mathrm{M} 0$ & $\|$ \\
\hline 07 & Male & 50 & Buccal mucosa & Mod. diff. SCC & T1NOMO & I \\
\hline
\end{tabular}

potential mechanism underlying these findings may be that the decreased expression of the two receptors leads to the decrease of T $\beta$ RII- or T $\beta$ RIII-mediated apoptosis. These studies, together with the present study, suggest a broad role for both T $\beta$ RII or T $\beta$ RIII as tumor suppressors in epithelial-derived malignancies.

Tumor occurrence and development are intrinsically correlated with the role of the surrounding stroma. In the current study, we demonstrated that T $\beta$ RII and T $\beta$ RIII played an important role in oral carcinogenesis. Did similar changes take place in tumor-associated stroma? Considering the complex composition of stroma, we chose to study CAFs as the object of our study, as these cells are considered crucial in the process of carcinogenesis. Carcinoma-associated fibroblasts (CAFs) have been regarded as a special kind of myofibroblasts, and they also were named as myofibroblasts in many reports $[10,13,20,21]$. The stromal microenvironment in human tumours play a key role in the formation of CAFs. This cell-type is mostly defined based on morphological characteristics, biological behavior (including promotion of tumor cell growth) [13] or the expression of markers such as a-smooth-muscle actin (a-SMA), fibroblast-activated protein (FAP), fibroblastspecific protein-1 (FSP1), neuron-glial antigen-2 (NG2) and PDGF $\beta$-receptor [10]. However, and a-SMA was mainly used to identify the CAFs $[10,13,20,21]$. In our study, the oral CAFs was also detected as expression of a-SMA. To verify our hypothesis, we first isolated and cultured seven primary CAF lines and then assessed the expression levels of T $\beta$ RI, T $\beta$ RII, and T $\beta$ RIII. Coupled with the IHC observations from OSCC, both T $\beta$ RII and T $\beta$ RIII were downregulated frequently at the mRNA and protein levels in human oral CAFs compared with NFs. A more pronounced decline was observed for the expression of T $\beta$ RIII compared with T $\beta$ RII (11.37 fold vs 2.013 fold). Bacman $\mathrm{D}$ et al considered that the decrease of TGF- $\beta$ receptor expression in stroma as in epithelial tumour tissue might occur via mutation or downregulation [16]. In addition, significant downregulation of T $\beta$ RII and T $\beta$ RIII was observed after treatment with TGF- $\beta 1$ for varying periods. Although we observed a slight increase in T $\beta$ RI expression, this observation was neither consistent nor significant. The mechanisms underlying the negative regulation mediated by TGF- $\beta 1$ implicate primarily genes that regulate the cell cycle, including the downregulation of growth-promoting transcription factors, such as c-Myc, ID1, and ID2 [22]. TGF- $\beta$ isoforms downregulate T $\beta$ RIII in breast cancer cells; this effect was relatively specific for T $\beta$ RIII, as it did not affect T $\beta$ RI and T $\beta$ RII $[19,23]$. However, here we demonstrated the loss of T $\beta$ RIII and T $\beta$ RII expression both in CAFs and in NFs after treatment with TGF- $\beta 1$. The previous report together with our current discoveries lead us to conclude that loss of the expression of T $\beta$ RIII and/or T $\beta$ RII in CAFs is a mechanism that underlies the tumor-promoting function of TGF$\beta 1$. How might the changes in the cellular characteristics of CAFs, together with the loss of T $\beta$ RII and T $\beta$ RIII expression and their response to TGF- $\beta 1$, affect oral carcinogenesis? The current results prompt us to hypothesize that the increase in the levels of expression of TGF- $\beta$ during tumor progression stimulates the downregulation of $\mathrm{T} \beta \mathrm{Rs}$, both in the tumor itself and in stroma (CAFs), which results in the T $\beta \mathrm{R}$-mediated reduction of apoptosis. Accordingly, loss of functional T $\beta$ RII and T $\beta$ RIII signaling may contribute to apoptotic escape and tumorigenesis.

At present, three main strategies are used to target CAFs during cancer therapy: (a) targeting of the CAF signals that initiate or promote tumor growth, invasion, and metastasis; (b) targeting of the tumor signals that are responsible for the development of "adequate" tumor fibroblasts; and (c) elimination of the CAFs themselves, to abolish all interactions among heterotypic cell types [21]. However, the tumor-host interaction microenvironment is a large and complex network; therefore, it remains questionable whether the use of one single factor (such as antibodies) is efficient in cancer therapy. Two large randomized trials in SCLC failed to show any benefits for inhibitor treatment [24]. Thus, it is necessary to exploit novel strategies that use CAFs 


\section{Cytokeratin}
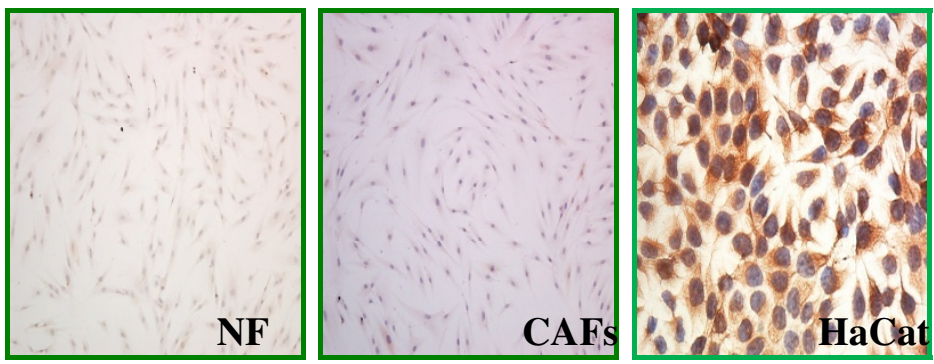

Vimentin

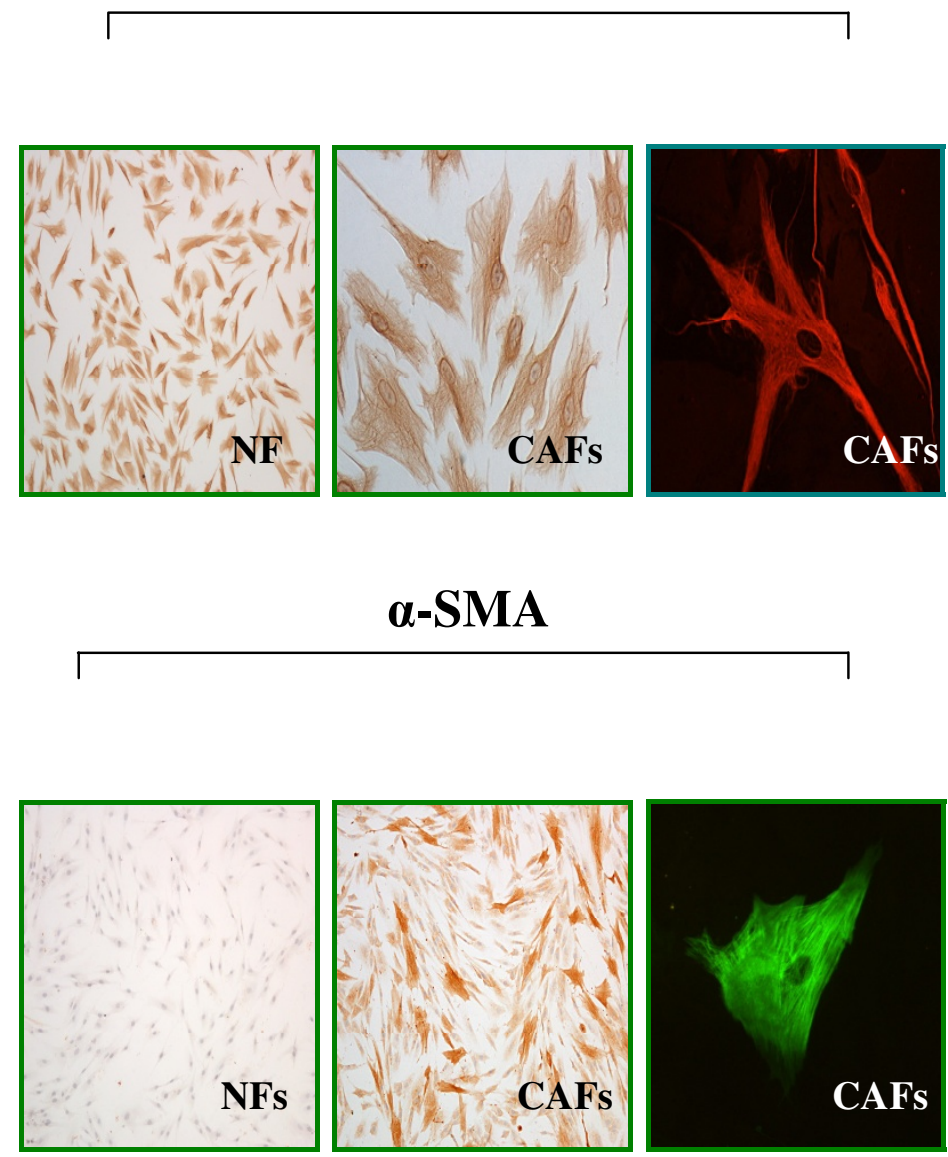

Figure 4 Identification of oral CAFs and NFs. The morphological characteristics of CAFs changed significantly compared with what was observed in NFs. CAFs showed positive staining for vimentin and $\alpha$-SMA and were negative for cytokeratin. The positive control (human normal keratinocytes HaCat) is shown for cytokeratin stain. 

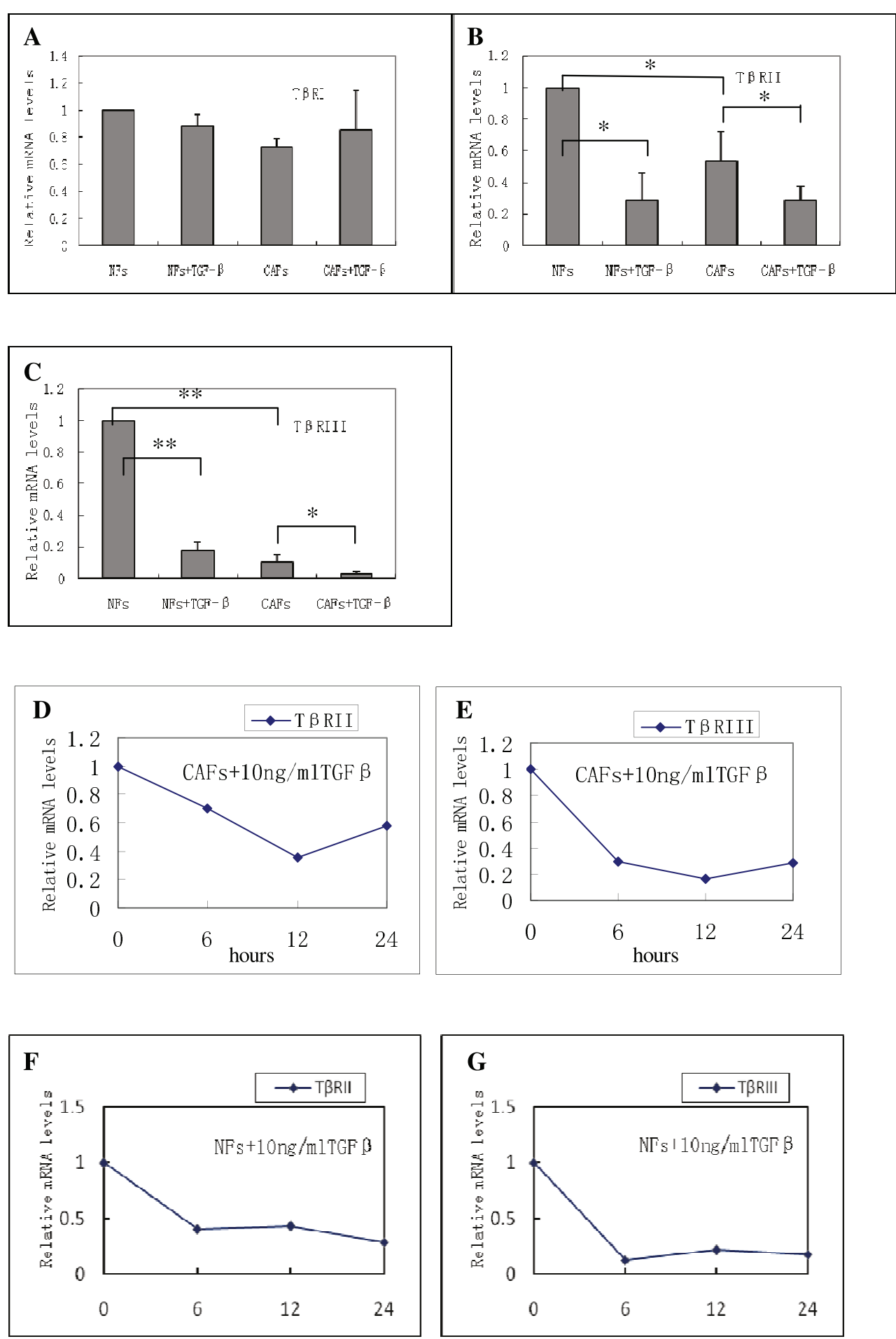

Figure 5 Quantitative real-time PCR analysis of the mRNA levels of T $\beta R I, T \beta R I I$, and T $\beta R$ III in CAFs and in CAFs in response to TGF- $\beta 1$ $(10 \mathbf{~ n g} / \mathbf{m l})$ stimulation. (A) The expression levels of T $\beta R$ I were not significantly different in CAFs and NFs ( $P=0.362)$; TGF- $\beta 1$ treatment didn't change the T $\beta R$ RI levels in CAFs or in NFs. (B) T $\beta R$ RI mRNA expression was reduced in CAFs compared with NFs ( $\left.{ }^{*} P=0.004\right)$; The levels of

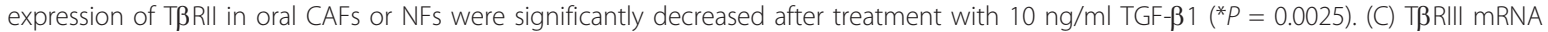
expression in CAFs was also significantly different from that of the control group $\left.{ }^{* *} P=0.001\right)$. The levels of expression of T $\beta$ RIII in oral CAFs or NFs were also significantly decreased after treatment with $10 \mathrm{ng} / \mathrm{ml}$ TGF- $\beta 1$ ( $\left.{ }^{* *} P=0.0035\right)$. (D, E) The maximal downregulation in oral CAFs with TGF- $\beta 1$ was observed at 6-12 h. (F, G) The maximal downregulation in NFs with TGF- $\beta 1$ was observed at 6 h. 


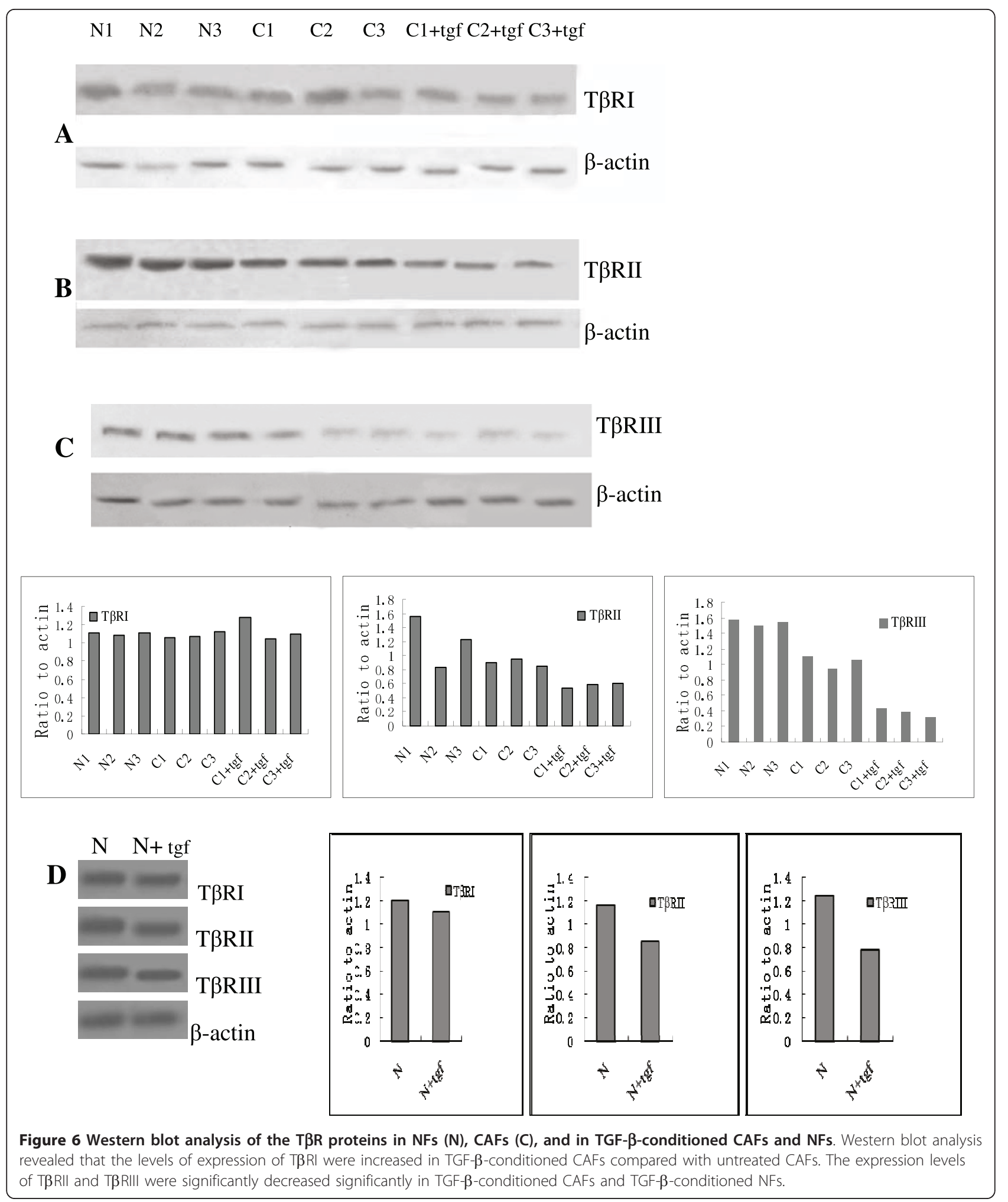


as targets in anticancer therapies. In the current study, we demonstrated that the expression of T $\beta$ RII and T $\beta$ RIII in oral epithelium and CAFs played an important role in tumorigenesis. In addition, the restoration of the expression levels of T $\beta$ RII and T $\beta$ RIII seems more feasible than prior strategies.

Taken together, these data suggest that the loss of the expression of T $\beta$ RII and T $\beta$ RIII in oral epithelium and stroma (CAFs) is a common event in OSCC patients. Therefore, we strongly believed that T $\beta$ RII and/or TRRIII may be used as predictors of tumorigenesis and severity and represent adequate therapeutic targets. However, the understanding of the precise mechanisms involved falls short of what would be required for the development of practical clinical applications. Moreover, the restoration of the expression levels of T $\beta$ RIII and $T \beta R I I$ in cancerous tissues of the oral mucosa may serve as a novel target for the treatment of oral carcinoma.

\section{Conclusions}

The expression of both T $\beta$ RII and T $\beta$ RIII was significantly downregulated in oral epithelium and stroma (CAFs) in OSCC. Exogenous TGF- $\beta 1$ could downregulate both T $\beta$ RII and T $\beta$ RIII in oral CAFs and in NFs. Moreover, the restoration of the expression levels of T $\beta$ RIII and T $\beta$ RII in cancerous tissues of the oral mucosa may serve as a novel target for the treatment of oral carcinoma.

\section{Acknowledgements}

This study was supported by grants from the National Natural Science Foundation of China (No. 30872873), the Doctoral Fund of the Ministry of Education of China (No. 20070610067).

\section{Author details \\ ${ }^{1}$ State Key Laboratory of Oral Diseases, Sichuan University, Chengdu, Sichuan, China. ${ }^{2}$ The Station Key Lab of Biotherapy, Sichuan University, Sichuan, China. ${ }^{3}$ Department of Oral Pathology, West China Hospital of Stomatology, Sichuan University, Sichuan, China. ${ }^{4}$ Department of Oral Oncology, West China Hospital of Stomatology, Sichuan University, Sichuan, China. ${ }^{5}$ Department of Oral Medicine, West China Hospital of Stomatology, Sichuan University, Sichuan, China.}

\section{Authors' contributions}

WXM carried out the experimental studies and drafted and completed the manuscript. QJX participated in the design of the study and performed the statistical analysis. LYW, SXC, XH and LZ participated the tissue collected and tumor pathological characteristics. HMZ and QHG conceived of the study and participated in the design and coordination as well as helped to draft the manuscript. All authors read and approved the final manuscript.

\section{Competing interests}

The authors declare that they have no competing interests.

Received: 18 August 2010 Accepted: 28 February 2011 Published: 28 February 2011

\section{References}

1. Elliott RL, Blobe GC: Role of transforming growth factor Beta in human cancer. J Clin Oncol 2005, 23:2078-2093.
2. Attisano L, Wrana JL: Signal transduction by the TGF-beta superfamily. Science 2002, 296:1646-1647.

3. Goggins M, Shekher M, Turnacioglu K, Yeo CJ, Hruban RH, Kern SE: Genetic alterations of the transforming growth factor beta receptor genes in pancreatic and biliary adenocarcinomas. Cancer Res 1998, 58:5329-5332.

4. Munoz-Antonia T, Muro-Cacho C, Sharma S, Cantor A, Bepler G: Expression of TGFbeta type-II receptor in association with markers of proliferation and apoptosis in premalignant lung lesions. Cancer 2007, 110:1527-1531.

5. Turley RS, Finger EC, Hempel N, How T, Fields TA, Blobe GC: The type III transforming growth factor-beta receptor as a novel tumor suppressor gene in prostate cancer. Cancer Res 2007, 67:1090-1098.

6. Margulis V, Maity T, Zhang XY, Cooper SJ, Copland JA, Wood CG: Type III transforming growth factor-beta (TGF-beta) receptor mediates apoptosis in renal cell carcinoma independent of the canonical TGF-beta signaling pathway. Clin Cancer Res 2008, 14:5722-5730.

7. Funk GF, Karnell LH, Robinson RA, Zhen WK, Trask DK, Hoffman HT: Presentation, treatment, and outcome of oral cavity cancer: a National Cancer Data Base report. Head Neck 2002, 24:165-180.

8. Mincione G, Di Marcantonio MC, Artese L, Vianale G, Piccirelli A, Piccirilli M, Perrotti $V$, Rubini C, Piattelli A, Muraro R: Loss of expression of TGF- $ß 1$, TßRI, and TßRIl correlates with differentiation in human oral squamous cell carcinomas. Int J Oncol 2008, 32(2):323-31.

9. Hui P, Shintaniy S, Kim Y, Wong DT: Loss of p12CDK2-AP1 Expression in human oral squamous cell carcinoma with disrupted transforming growth factor- $\beta$-Smad signaling pathway. Neoplasia 2006, 8:1028-1036.

10. Ostman A, Augsten M: Cancer-associated fibroblasts and tumor growthbystanders turning into key players. Current Opinion in Genetics \& Development 2009, 19:67-73.

11. Kiaris H, Trimis G, Papavassiliou AG: Regulation of tumor-stromal fibroblast interactions: implications in anticancer therapy. Current Medicinal Chemistry 2008, 15:3062-3067.

12. Olumi AF, Grossfeld GD, Hayward SW, Carroll PR, TIsty TD, Cunha GR: Carcinoma-associated fibroblasts direct tumor progression of initiated human prostatic epithelium. Cancer Res 1999, 59:5002-5011.

13. Orimo A, Gupta PB, Sgrol DC, Arenzana-Seisdedos F, Delaunay T, Naeem R, Carey VJ, Richardson AL, Weinberg RA: Stromal fibroblasts present in invasive human breast carcinomas promote tumor growth and angiogenesis through elevated SDF-1/CXCL12 secretion. Cell 2005, 121:335-348.

14. Liu Y, Hu T, Shen J, Li SF, Lin JW, Zheng XH, Gao QH, Zhou HM: Separation, cultivation and biological characteristics of oral carcinomaassociated fibroblasts. Oral Dis 2006, 12:375-380.

15. Bhowmick NA, Neilson EG, Moses HL: Stromal fibroblasts in cancer initiation and progression. Nature 2004, 432:332-337.

16. Bacman D, Merkel S, Croner R, Papadopoulos T, Brueckl W, Dimmler A: TGFbeta receptor 2 downregulation in tumour-associated stroma worsens prognosis and high-grade tumours show more tumour-associated macrophages and lower TGF-beta1 expression in colon carcinoma: a retrospective study. BMC Cancer 2007, 7:156.

17. Sousa AM, Liu T, Guevara O, Stevens J, Fanburg BL, Gaestel M, Toksoz D, Kayyali US: Smooth muscle alpha-actin expression and myofibroblast differentiation by TGFbeta are dependent upon MK2. J Cell Biochem 2007, 100:1581-1592.

18. Gordon KJ, Mei D, Chislock EM, Field TA, Blobe GC: Loss of type III transforming growth factor $b$ receptor expression increases motility and invasiveness associated with epithelial to mesenchymal transition during pancreatic cancer progression. Carcinogenesis 2008, 29:252-262.

19. Dong M, How T, Kirkbride KC, Gordon KJ, Lee JD, Hempel N, Kelly P, Moeller BJ, Marks JR, Blobe GC: The type III TGF-beta receptor suppresses breast cancer progression. J Clin Invest 2007, 117:206-217.

20. Hwang RF, Moore T, Arumugam T, Ramachandran V, Amos KD, Rivera A Ji B, Evans DB, Logsdon CD: Cancer-associated stromal fibroblasts promote pancreatic tumor progression. Cancer Res 2008, 68:918-926.

21. Micke $P$, Ostman A: Tumour-stroma interaction: cancer-associated fibroblasts as novel targets in anti-cancer therapy? Lung Cancer 2004, 45: S163-S175.

22. Kang Y: A self-enabling TGFbeta response coupled to stress signaling: Smad engages stress response factor ATF3 for Id1 repression in epithelial cells. Mol Cell 2003, 11:915-926.

23. Hempell N, How T, Cooper SJ, Green TR, Dong M, Copland JA, Wood CG, Blobe GC: Expression of the type III TGF-b receptor is negatively regulated by TGF-beta. Carcinogenesis 2008, 29:905-912. 
24. Shepherd FA, Giaccone G, Seymour L, Debruyne C, Bezjak A, Hirsh V, Smylie M, Rubin S, Martins H, Lamont A, et al: Prospective, randomized, double-blind, placebo-controlled trial of marimastat after response to first-line chemotherapy in patients with small-cell lung cancer: a trial of the National Cancer Institute of Canada-Clinical Trials Group and the European Organization for Research and Treatment of Cancer. J Clin Oncol 2002, 20:4434-4439.

Pre-publication history

The pre-publication history for this paper can be accessed here: http://www.biomedcentral.com/1471-2407/11/88/prepub

doi:10.1186/1471-2407-11-88

Cite this article as: Meng et al: Downregulation of TGF-beta receptor types II and III in oral squamous cell carcinoma and oral carcinomaassociated fibroblasts. BMC Cancer 2011 11:88.

\section{Submit your next manuscript to BioMed Central} and take full advantage of:

- Convenient online submission

- Thorough peer review

- No space constraints or color figure charges

- Immediate publication on acceptance

- Inclusion in PubMed, CAS, Scopus and Google Scholar

- Research which is freely available for redistribution

Submit your manuscript at www.biomedcentral.com/submit 